\title{
MAKA: ANTARA FAKTA DAN TATA BAHASA DALAM BAHASA INDONESIA
}

\section{MAKA: BETWEEN FACT AND STRUCTURE IN BAHASA INDONESIA}

\section{Umi Kulsum, Cece Sobarna, Tajudin Nur, Wagiati}

\author{
Universitas Padjadjaran
}

Jalan Raya Bandung - Sumedang Km 21, Jatinangor, Sumedang, Jawa Barat

Ponsel: 082121910879: Pos-el: umikulsum_1973@yahoo.co.id

\begin{abstract}
Abstrak
Banyaknya pemakaian maka dalam kondisi berbahasa Indonesia sekarang bertolak belakang dengan kajian atau bahasan mengenai maka. Tidak ditemukan tulisan pakar yang membahas maka secara terperinci, termasuk dalam Tata Bahasa Baku Bahasa Indonesia yang hanya menyebutkan maka sebagai konjungtor subordinatif hasil. Uraian mengenai maka yang agak lengkap justru ditemukan dalam Kamus Umum Bahasa Indonesia karya W.J.S. Poerwadarminta yang sudah cukup lama terbit. Tulisan ini mencoba mengamati maka dari sisi kenyataan (fakta) yang ada dan dari sisi tata bahasa. Maka dalam tulisan ini ditinjau atas perilaku sintaksis, makna, dan bentuknya. Berdasarkan perilaku sintaksis dan makna, maka yang mengikuti anak kalimat mempunyai frekuensi kemunculan yang paling banyak (jika..., maka....). Batas maka sebagai konjungtor antarkalimat dan konjungtor antarklausa sangat tipis, apalagi dalam ragam lisan. Berdasarkan bentuknya dapat dinyatakan bahwa sebagian besar maka merupakan konjungsi dasar (tidak bergabung dengan bentuk lain). Akan tetapi, ada juga modifikasi maka, yaitu bergabung dengan -nya dan bergabung dengan dari itu.
\end{abstract}

Kata Kunci: maka; konjungtor; bahasa Indonesia 


\begin{abstract}
Many of the use of maka in Indonesia language is contrary to the research or discussion concerning maka itself. There is no linguistic expert discussing maka in details and complete, even in the book of Tata Bahasa Bahasa Indonesia. maka is mentioned in the book only as a subordinative conjuction and no details discussion on it. In fact, maka is described more completely In Kamus Umum Bahasa Indonesia by W.J.S. Poerwadarminta written long time ago. This study observes maka regarding its usage in daily communication and its factual structural form. Maka here will be studied through its syntactic behavior, meaning, and form. In accordance with its syntactic behavior and meaning, maka following defendent cluase frequently accures more often, in the form of jika ....., maka....(if...., then...). The boundry whether to be intersentence conjunctor and sentence conjuctor is very thin, moreover in spoken language. Basically, in accordance with its form, maka is categorised as single conjunctor that can stand alone to make meaning. Yet, there is other modification regarding the use of maka, where -nya is affixed with it or phrase dari itu is used along with.
\end{abstract}

Keywords: maka (then); conjunctor; Indonesian language

\section{Pendahuluan}

Tulisan ini mencoba mengungkap satu aspek yang bentuknya kecil, yaitu salah satu kata tugas dalam bahasa Indonesia. Tulisan ini diilhami ketika menyunting naskah yang mengandung jika (atau sejenisnya) yang diikuti oleh maka, sebagai contoh

(1) Apabila terjadi perbedaan persentase residu bagian atas dan persentase residu bagian bawah lebih kecil dari persentase aspal hasil destilasi, maka pengujian harus diulang. Kalimat

(1) disarankan diperbaiki dengan menghilangkan maka. Akan tetapi, pengonsep tidak mau menghilangkan maka dengan alasan jika maka dihilangkan, kalimat menjadi kurang tegas atau kurang adanya penekanan/ penegasan. Bahkan, informan tersebut beranggapan bahwa apabila dan maka pada contoh kalimat tersebut merupakan satu kesatuan yang tidak terpisahkan. Mereka tidak dapat menerima alasan bahwa dengan hadirnya maka, contoh (1) tidak mempunyai induk kalimat karena kedua klausa tersebut merupakan anak kalimat.

Rasa penasaran dengan kenyataan tersebut mendorong penulis untuk mencari teori yang 
terkait dengan maka dalam Tata Bahasa Baku Bahasa Indonesia, Kamus Besar Bahasa Indonesia, buku terbitan Pusat Bahasa, dan buku yang terkait dengan sintaksis bahasa Indonesia. Hasilnya sungguh mencengangkan karena selain yang dicari tidak ada, dalam Tata Bahasa Baku Bahasa Indonesia Edisi ketiga yang terbit tahun 2000 , secara tidak sengaja, ditemukan 101 bentuk sebagainya contoh (1), yaitu sebuah konjungtor subordinatif syarat (jika, karena, kalau, apabila, bila, seandainya, andaikata, dan mengingat) diikuti oleh maka. Jumlah ini jauh lebih besar daripada jumlah konjungtor subordinatif syarat yang tidak diikuti oleh maka, yang hanya berjumlah 66 .

KBBI menunjukkan hal yang serupa. Pada KBBI (2005:700) dinyatakan bahwa maka p 1 kata penghubung untuk menyatakan hubungan akibat, implikasi, contoh karena saya tidak dapat mengetik dengan baik, maka surat undangan itu saya tulis tangan saja. Dapat dinyatakan bahwa contoh kalimat yang mengandung maka merupakan kalimat yang yang mengandung konjungtor lain sebelumnya, yaitu karena. Contoh yang ada dalam Tata Bahasa Baku dan KBBI bertolak belakang dengan dengan ketidakbolehannya dua konjungtor bergabung dalam satu kalimat.

Selain itu, hal yang mendasari tulisan ini adalah banyaknya frekuensi kemunculan maka (terutama yang bergabung dengan konjungtor lain sebelumnya) dan dalam tulisan ini maka tidak hanya dibatasi pada kalimat yang mengandung konjungtor subordinatif syarat $(j i k a \ldots \quad m a k a \ldots .$.$) , tetapi$ seluruh bentuk maka yang ditemukan di dalam data.

Maka merupakan salah satu kata tugas bahasa Indonesia yang yang bentuknya tentu kecil dan "nyaris terlupakan". Akan tetapi, cukup banyak hal yang dapat diungkap terkait dengannya.Dalam tulisan ini diungkap perilaku sintaksis, makna, dan bentuk maka dalam bahasa Indonesia.Dengan demikian, masalah dalam tulisan ini dapat dijabarkan sebagai berikut.

a. Bagaimana perilaku sintaksis dan makna maka dalam kalimat bahasa Indonesia? 
Maka: Antara Fakta dan...

b. Dengan bentuk apa saja maka bergabung dalam membentuk sebuah konjungtor?

\section{Landasan Teori}

Maka termasuk kata tugas dalam bahasa Indonesia. Sebagaimana telah diungkap di awal bahwa maka tidak banyak dikupas dalam tata bahasa Indonesia. Dari data yang ada, ditemukan bahwa sebagian besar maka bergabung dengan konjungsi subordinatif syarat. Berikut disajikan beberapa pendapat terkait dengan konjungtor subordinatif syarat, konjungtor subordinatif hasil, konjungtor korelatif, dan partikel yang keempatnya sangat erat hubungannya dengan maka yang dapat diuraikan sebagai berikut.

Alwi et al. (2000:299) menyatakan bahwa contoh konjungtor subordinatif syarat ialah jika, kalau, jikalau, asal(kan), bila dan manakala. Lebih lanjut Alwi et al. (2000:406) menyatakan bahwa hubungan syarat terdapat dalam kalimat yang klausa subordinatifnya menyatakan syarat terlaksananya apa yang disebut dalam klausa utama. Subordinator yang lazim dipakai adalah jika(lau), kalau, dan asal (kan). Di samping itu, subordinatior kalau, (apa)bila, dan bilamana juga dipakai jika syarat itu bertalian dengan waktu. Selain itu, dalam buku yang lain Alwi (Peny. [2001]) menyatakan bahwa anak kalimat keterangan syarat ini menyatakan syarat terlaksananya apa yang disebutkan pada induk kalimat. Kata penghubung yang digunakan ialah jika, jikalau, kalau, seandainya, andaikata, andaikan, asalkan, bila, bilamana, dan umpama, contohnya ialah Kalau kamu kerjakan dengan komputer, pekerjaan itu akan cepat selesai.

Selain konjungtor subordinatif syarat, Alwi et al. (2000:409) menyatakan bahwa hubungan hasil terdapat dalam kalimat majemuk yang klausa subordinatifnya menyatakan hasil atau akiabat dari apa yang dinyatakan dalam klausa utama; hubungan ini biasanya dinyatakan dengan memakai subordinator seperti, sehingga, sampai(-sampai), dan maka. Contohnya ialah Kami tidak setuju, maka kami pun protes.

Partikel dalam tulisan ini didefinisikan sebagai kata tugas yang 
memiliki bentuk khusus, yaitu sangat ringkas atau bentuknya kecil (satu silabel) dan mempunyai fungsifungsi dan makna-makna tertentu. Alwi et al. (2000:307) menyatakan bahwa partikel penegas meliputi kata yang tidak tertakluk pada perubahan bentuk dan hanya berfungsi menampilkan unsur yang diiringinya.

\section{Metode Penelitian}

Metode penelitian yang digunakan ialah metode deskriptif komparatif. Pengambilan data dilakukan dengan observasi dan studi pustaka, sedangkan teknik kajian yang digunakan ialah teknik pelesapan, penyulihan, dan permutasian.

Data yang digunakan berasal dari Tata Bahasa Baku Bahasa Indonesia, surat kabar Pikiran Rakyat, majalah Kawanku, tabloid Gaul, tabloid Ngabaraga, novel Ayat-Ayat Cinta karya Habiburrahman El Shirazy, novel The Kid karya Kevin Lewis, buku Kimia untuk SMU kelas XII, artikelartikel kesehatan dan agama dalam webside, beberapa skripsi dan disertasi, terjemahan Almasurat, $e$ - book Islami dan beberapa hikayat untuk data bahasa Melayu.

\section{Pembahasan}

Maka diungkap berdasarkan perilaku sintaksis, makna, dan bentuknya dalam bahasa Indonesia.

\subsection{Berdasarkan Perilaku Sintaksis dan Makna}

\section{A. Mengikuti Anak Kalimat}

Maka yang mengikuti anak

kalimat mempunyai frekuensi kemunculan yang paling banyak. Jika maka dianggap konjungtor subordinatif, kalimat yang mengandungnya dianggap tidak berinduk karena klausa sebelumnya juga berupa anak kalimat. Ketika dicek kepada informan, mereka menyatakan bahwa kehadiraan maka yang mengikuti anak kalimat tersebut berfungsi penegas atau penekan. Posisi maka terletak pada klausa yang kedua atau klausa selanjutnya (tidak ada yang berposisi pada klausa pertama dan kemungkinan permutasian ke klausa pertama menghasilkan kalimat yang tidak berterima). Perilaku maka seperti ini dapat diklasifikasikan lagi menjadi beberapa hal yang dapat dijabarkan sebagai berikut. 


\section{1) Mengandung Konjungtor Subordinatif Syarat \\ Pada kalimat yang}

mengandung konjungtor subordinatif syarat, maka dapat mengikuti konjungtor jika, apa(bila), dan kalau. Hal tersebut dapat dilihat pada contoh berikut.

(2) Jika di dalam wilayah pemakaiannya orang tidak mudah berhubungan, misalnya karena tempat kediamannya dipisahkan oleh pegunangan, selat, atau laut, maka lambat-laun logat itu dalam perkembangannya akan banyak berubah sehingga dianggap bahasa yang berbeda.

(3) Bila kemudian kita tambahkan intonasi yang naik, lalu turun pada kata mobil maka terbentuklah kalimat yang merupakan pernyataan berita.

(4) Apabila intonasi naik, atau tanda bacanya adalah tanya, maka yang terbentuk adalah kalimat tanya.

(5) Kalau dipakai formula untuk membedakan idiom dengan verba majemuk maka perbedaan itu adalah sebagai berikut.

2) Mengandung Konjungtor Subordinatif Pengandaian Pada kalimat yang mengandung konjungtor subordinatif pengandaian, maka dapat mengikuti konjungtor seandainya dan andaikata. Hal tersebut dapat dilihat pada contoh berikut.
(6) Seandainya kalimat itu dipakai, maka akan muncullah citra yang khusus mengenai $\mathrm{Bu}$ Fatimah dan suaminya serta Tuti dan Johan

(7) Andaikata dia mengatakan hal itu, maka pasti orang tuanya tidak akan marah.

3) Mengandung Konjungtor Subordinatif Berupa Pronomina Penanya pada kalimat yang mengandung konjungtor subordinatif yang berupa pronominal penanya, maka dapat mengikuti konjungtor barang(siapa). Hal tersebut dapat dilihat pada contoh berikut.

(8) Barangsiapa yang mengangkat seseorang karena hubungan kekerabatan dan kedekatan sementara ada orang lain yang lebih pantas dan ahli daripadanya, maka sesungguhnya dia telah melakukan pengkhianatan terhadap Allah dan Rasulnya dan juga pengkhianatan kepada orang-orang yang beriman (H.R. Hakim).

(9) Siapa yang memberi pinjaman dengan nama Allah maka Allah melipatgandakan balasannya.

4) Mengandung Konjungtor Subordinatif Sebab

Pada kalimat yang

mengandung konjungtor subordinatif sebab, maka dapat mengikuti konjungtor karena(nya), dan mengingat. Hal tersebut dapat dilihat pada contoh berikut. 
(10) Karena tiap masyarakat bahasa memiliki ragam lisan, sedangkan ragam tulisan baru muncul kemudian, maka soal yang perlu ditelaah ialah bagaimana orang menuangkan ujurannya ke dalam bentuk tulisan.

(11) Mengingat pernyataannya berlebih-lebihan, maka hakim memberatkan sanksi terhadapnya.

5) Mengandung Konjungtor Subordinatif Tujuan Pada kalimat yang mengandung konjungtor subordinatif tujuan, maka dapat mengikuti konjungtor agar dan untuk. Hal tersebut dapat dilihat pada contoh berikut.

Untuk memudahkan orangorang memasuki pintu surga, maka selama bulan ramadan iblis pun dibelenggu

Agar dapat berjalan dengan efektif, maka masing-masing individu harus mengetahui komitmen mereka dan harus siap bertindak sebagai suatu kesatuan.

6) Mengandung Konjungtor Subordinatif Waktu

Pada kalimat yang

mengandung konjungtor subordinatif waktu, maka dapat mengikuti konjungtor setelah. Hal tersebut dapat dilihat pada contoh berikut.

(14) Setelah melalui mekanisme penyelesaian administrasi, maka dalam dua hingga tiga hari ke depan, kami akan mulai memanggil mereka untuk diperiksa.

(11/Nov/08/4/1)

\section{B. Mengikuti Keterangan dan Konjungtor Lain \\ Dalam kategori ini, jika maka} dikategorikan sebagai konjungtor, kalimat menjadi tidak berinduk karena bentuk sebelumnya bukan klausa, melainkan keterangan atau konjungtor. Ketika dicek kepada informan, mereka menyatakan bahwa kehadiraan maka yang mengikuti keterangan atau konjungtor lain tersebut berfungsi penegas atau penekan. Posisi maka terletak setelah keterangan atau konjungsi lain. Maka yang mengikuti keterangan dan konjungtor lain berfungsi sebagai penegas/penekan. Hal itu dapat dilihat pada contoh berikut.

Dengan batasan itu, maka sebuah morfem dapat berupa kata (seperti besar di atas), tetapi sebuah kata dapat terdiri atas satu morfem atau lebih.

Maka yang diikuti konjungtor lain dapat dilihat pada contoh berikut.

(18) Dengan demikian, maka jelas apa dan bagaimana YPK sebagai pusat kegiatan seni di Bandung. 


\section{Sebagai Konjungtor Antarklausa}

Dari data yang ada dapat dinyatakan bahwa batas maka sebagai konjungtor antarkalimat dan konjungtor antarklausa sangat tipis, apalagi dalam ragam lisan.Maka sebagai konjungtor antarklausa juga mempunyai frekuensi kemunculan yang banyak.Jika maka dianggap konjungtor antarkalimat, kalimat yang mengandungnya merupakan kalimat yang dianggap gramatikal karena klausa sebelumnya sudah berupa induk kalimat (berbeda dengan A, yang berupa anak kalimat atau B yang berupa keterangan/konjungtor). Posisi maka terletak pada klausa yang kedua (tidak ada yang berposisi pada klausa pertama dan kemungkinan permutasian ke klausa pertama menghasilkan kalimat yang tidak berterima). Perilaku maka seperti ini dapat diklasifikasikan lagi menjadi beberapa hal, yaitu menyatakan (1) hasil, (2) akibat/alasan, dan (3) keterangan. Ketiganya dijabarkan sebagai berikut.

\section{1) Menyatakan Hasil}

Maka sebagai konjungtor antarklausa yang menyatakan hasil dapat dilihat pada contoh berikut.
(19) Ia perhatian terhadap seni tradisonal maka bersama Paguyuban Doelloer ia menciptakan iklim itu.

\section{2) Menyatakan Akibat/Alasan}

Maka sebagai konjungtor
antarklausa yang menyatakan
akibat/alasan dapat dilihat pada
contoh berikut.
(22) Dan (ingatlah) hari (ketika)
ditiup sangkakala, maka
terkejutlah segala yang di
langit dan yang di bumi,
kecuali yang dikehendaki
Allah.

\section{3) Menyatakan Keterangan}

$$
\begin{aligned}
& \qquad \text { Maka sebagai konjungtor } \\
& \text { antarklausa yang menyatakan } \\
& \text { keterangan dapat dilihat pada contoh } \\
& \text { berikut. }
\end{aligned}
$$

(27) Saum bulan Ramadan itu sama dengan 10 bulan dan saum 6 hari sama dengan dua bulan, maka demikianlah sama dengan saum satu tahun

D. Sebagai Antarkalimat

Maka yang berperilaku sebagai konjungstor antarkalimat cukup banyak, terutama dari sumber data yang bersifat Islami. Sebagai konjungtor antarkalimat, maka berfungsi sebagai konjungtor yang 
menyatakan hasil. Posisi maka diawal kalimat dan umumnya diikuti oleh tanda koma.Hal tersebut dapat dilihat pada contoh berikut.

(30) Kalau mereka nilai lamban benar juga karena ada pergeseran dan tidak bisa dihindari. Maka, sekarang kita instruksikan daerahdaerah dipacu kuat untuk bisa menyelesaikan, katanya. (11/Nov/08/2/5)

\section{E. Sebagai Konjungtor Antarparagraf}

Maka yang berperilaku sebagai konjungsi antarparagraf tidak banyak. Sebagai konjungtor antarparagraf, maka berfungsi sebagai konjungtor yang menyatakan hasil dan berposisi di awal paragraf. Hal tersebut dapat dilihat pada contoh berikut.

$$
\begin{aligned}
& \text { Maka dalan even Braga } \\
& \text { Festival } 2009 \text { ini seharusnya } \\
& \text { menjadi momentum yang } \\
& \text { dilakukan pementintah untuk } \\
& \text { membangun. }
\end{aligned}
$$

\subsection{Berdasarkan Bentuknya}

$$
\begin{aligned}
& \text { Sebagian besar maka } \\
& \text { merupakan konjungsi dasar (tidak } \\
& \text { bergabung dengan bentuk lain), } \\
& \text { sebagaimana beberapa contoh yang } \\
& \text { telah dikemukakan sebelumnya. } \\
& \text { Akan tetapi, ada juga modifikasi } \\
& \text { maka (bergabung dengan bentuk } \\
& \text { lain). }
\end{aligned}
$$

\section{A. Bergabung dengan -nya}

Maka dapat bergabung dengan -nya dan menyatakan hasil/akibat.Contohnya dapat dilihat pada kalimat berikut.

Aku kan suka traveling. Makanya aku suka bawainin acara ini

\section{B. Bergabung dengan dari itu}

Selain dengan -nya, maka dapat bergabung dengan dari itu dan menyatakan hasil/akibat. Contohnya dapat dilihat pada kalimat berikut.

$$
\begin{aligned}
& \text { Ayu selalu bicara sendiri } \\
& \text { dalam bahas Inggris. Maka } \\
& \text { dari itu ayahnya pernah } \\
& \text { menyuruhnya berbicara di } \\
& \text { depan keluarga besarnya. }
\end{aligned}
$$

\section{Penutup}

Maka, walaupun kecil dan "nyaris terlupakan", cukup banyak yang dapat diungkap darinya. Beberapa hal yang dapat disimpulkan dari tulisan ini adalah sebagai berikut.

1) Berdasarkan perilaku sintaksisnya, maka (a) mengikuti anak kalimat dengan frekuensi kemunculan yang paling tinggi (walaupun kehadirannya "tidak diperbolehkan") dan dapat diklasifikasikan lagi atas gabungan maka dengan [1] konjungtor subordinatif syarat (jika, 
apa(bila), kalau); [2] konjungtor

subordinatif pengandaian

(seandainya dan andaikata); [3] konjungtor subordinatif yang mengandung pronomina penanya (barang[siapa]); [4] konjungtor subordinatif sebab (karena, karenanya, mengingat); [5] konjungtor subordinatif tujuan (agar, untuk); [6] konjungtor subordinatif waktu (setelah); (b) sebagai konjungtor yang diikuti keterangan dan konjungtor lain ("kehadirannya juga tidak diperbolehkan", menyatakan hasil, dan berfungsi sebagai penegas); (c) sebagai konjungtor antarklausa (menyatakan hasil, alasan/akibat, dan keterangan), (d) sebagai konjungtor antarkalimat (menyatakan hasil); (e) sebagai konjungtor antarparagraf;. Batas maka sebagai konjungtor antarkalimat dan konjungtor antarklausa sangat tipis, apalagi dalam ragam lisan. Posisi maka pada bagian (1), (2), dan (3) berada di tengah kalimat, sedangkan pada bagian (4) dan (5) berada di awal kalimat.
2) Berdasarkan bentuknya dapat dinyatakan bahwa sebagian besar maka merupakan konjungsi dasar (tidak bergabung dengan bentuk lain). Akan tetapi, ada juga modifikasi maka (bergabung dengan bentuk lain), yaitu bergabung dengan -nya dan bergabung dengan dari itu. Keduanya menyatakan hasil/ akibat.

\section{Daftar Pustaka}

Alwi, Hasan et al. 2000. Tata Bahasa Baku Bahasa Indonesia.Edisi Ke-3. Jakarta: Balai Pustaka.

Alwi, Hasan (Peny.). 2001. Bahan Penyuluhan Bahasa Indonesia: Kalimat. Pusat Bahasa, Depdiknas.

Kridalaksana, Harimurti et al. 1985. Tata Bahasa Deskriptif Bahasa Indonesia: Sintaksis. Jakarta: Pusat Pembinaan dan Pengembangan Bahasa.

Lumintaintang, Yayah B. Mugnisjah. 1997. "Ketidakcermatan Pemakaian Kata Tugas Cermin Ketidakapikan Penalaran Berbahasa Indonesia". Dalam Jurnal Bahasa dan Sastra.

Lumintaintang, Yayah B. Mugnisjah. 1997. "Bahan Seminar Sehari dalam Rangka Bulan Bahasa 
MGMP SMU 13”. Jakarta, 22

November 1997.

Mutiara, Putri Minerva. 1993. Sejarah Melayu. Jakarta: Pusat Pembinaan dan

Pengembangan Bahasa.

Poerwadarminta, W.J.S. 1982.Kamus

Umum Bahasa Indonesia.

Jakarta: Balai Pustaka.

Soenardji. 1988. "Sudut Pandangan Pendidikan tentang Preposisi dan Konjungsi dalam Pembahasan Tata Bahasa Indonesia Baku". Dalam Seminar Tata Bahasa Baku Bahasa Indonesia.Jakarta Pusat Pembinaan dan Pengembangan Bahasa.

Tim Penyusun Kamus Pusat Bahasa. 2005. Kamus Besar Bahasa Indonesia.Edisi Ke-3, Cetakan Ke-3. Jakarta: Balai Pustaka. 
